\title{
Significant Predictors of Sports Performance in Elite Men Judo Athletes Based on Multidimensional Regression Models
}

\author{
Maciej Kostrzewa ${ }^{1}$, Radosław Laskowski ${ }^{2}$, Michal Wilk ${ }^{1}$, Wiesław Błach ${ }^{3}{ }^{(D)}$, \\ Angelina Ignatjeva ${ }^{1}$ and Magdalena Nitychoruk ${ }^{1, *(1)}$ \\ 1 Institute of Sport Sciences, The Jerzy Kukuczka Academy of Physical Education, 40-065 Katowice, Poland; \\ m.kostrzewa@awf.katowice.pl (M.K.); m.wilk@awf.katowice.pl (M.W.); \\ angelina.ignatjeva09@gmail.com (A.I.) \\ 2 Department of Physiology and Biochemistry, Gdansk University of Physical Education and Sport, \\ 80-336 Gdańsk, Poland; radoslaw.laskowski@awf.gda.pl \\ 3 Department of Sport, University School of Physical Education, 51-612 Wrocław, Poland; \\ wieslaw.blach@awf.wroc.pl \\ * Correspondence: magda.aneta.krawczyk@gmail.com; Tel.: +48-518-443-073
}

Received: 8 October 2020; Accepted: 4 November 2020; Published: 6 November 2020

\begin{abstract}
Background: This research aimed to identify the most significant predictors of sports level using regression modeling. Methods: This study examined 16 judokas (aged $23( \pm 2.5)$ ) from four weight categories, with four athletes in each category $(66 \mathrm{~kg}, 73 \mathrm{~kg}, 81 \mathrm{~kg}$ and $90 \mathrm{~kg})$. Each athlete was a member of the Polish National Team, an international master class (IM) or national master class (M). The tests were carried out twice (every two weeks) during the pre-competitive season in the morning, after a 10-min warm-up. The tests were performed according to the following protocol: Explosive Strength Lower Limbs (ExSLL) [W], Strength Endurance Lower Limbs (SELL) [\%], Explosive Strength Upper Limbs (ExSUL) [W], Strength Endurance Upper Limbs (SEUL) [\%]. The relationships between the dependent variable (ranking score) and the other analyzed variables (predictors) were estimated using the one-factor ridge regression analysis. Results: There were significant intergroup and intragroup differences in the results of explosive strength and strength endurance of the lower and upper limbs. The best predictors were identified using regression modeling: ExSLL, SELL, and SEUL. Conclusions: Increasing the value of these predictors by a unit should significantly affect the scores in the ranking table. Correlation analysis showed that all variables that are strongly correlated with the Polish Judo Association (PJA) ranking table scores may have an effect on the sports performance.
\end{abstract}

Keywords: judo; regression models; combat sports

\section{Introduction}

Sports performance is a multifactorial trait resulting from the interplay of individual, environmental, and task characteristics. Due to its complex, dynamic, and multidimensional nature, understanding the performance variability among athletes requires the adoption of a holistic perspective, which considers the integration of the levels, interacting at different scales during the performance [1]. The nature of combat sport is to strike, throw or grapple with an opponent [2]. Judo is a predominantly anaerobic, intermittent combat sport [3]. The effects of recovery type after judo combat on blood lactate removal and on performance in an intermittent anaerobic task requiring strength are explored [4]. Differences in fat-free mass and muscle thickness at various sites relate to performance level among judo athletes' quickness, balance, and explosiveness [5]. Strength, correct posture, effective movements, 
and balance are critical in judo. Due to the complexity of movements, judo can be considered as a tool to increase strength of postural muscles [6]. Sporting performance is a multi-factor phenomenon and is affected by motor [7,8], technical and tactical [9,10], and mental preparation [11]. Explosive strength and strength endurance are particularly important in judo, since these abilities are correlated with the sports level of elite athletes. Explosive strength determines the performance of dynamic movement activities, sudden body turns, jumps, kicks, or change of directions of movement. Furthermore, strength endurance allows for generating submaximum power repeatedly during the fight $[12,13]$.

The research carried out among national and international athletes allows for the determination of this dependence and increases their substantive and indirect predictive value. Above all, the analysis of explosive strength and strength endurance of judo athletes at elite levels can improve the efficiency of the training process and thus the effectiveness of their technique [14]. A comprehensive process of a certain strength training consists of properly planned tempo of exercises, number of repetitions and sets, external load, rest intervals, type of contraction, the choice of exercises and their sequence [15-18]. The analysis of the technique of performing a resistance exercise, as well as many more details related to somatic and anthropometric changes during the athletes development makes sports training more and more sophisticated while the coaching staffs are supported by specialists from various fields of science, and the athlete becomes a source of valuable [19-21]. Sports forecasting is usually treated as a classification problem where one class (win, lose or draw) can be predicted [22]. A large number of functions can be collected in sports forecasts. Especially in judo, there are many factors that can be used to predict a sporting result. Therefore, our research aimed to identify the most important of the selected sport level predictors using regression modeling.

\section{Materials and Methods}

\subsection{Participants}

The research material included the results of tests in an elite male judo athlete, selected based on mixed sampling. At the time of the research, each athlete was a member of the Polish National Team, an international master class (IM) or national master class (M). The sports level of the athletes was determined based on their place in the ranking of the Polish Judo Association (PJA) [23]. The study examined 16 athletes from four weight categories, with 4 athletes in each category $(66 \mathrm{~kg}, 73 \mathrm{~kg}, 81 \mathrm{~kg}$ and $90 \mathrm{~kg}$ ). The descriptive characteristics of particular groups are presented in Table 1:

Table 1. Descriptive statistics of characteristics variables for the 4 weight categories of judokas (mean and (SD)).

\begin{tabular}{ccccc}
\hline Parameters & $<66 \mathbf{~ k g}$ & $<73 \mathbf{~ k g}$ & $<\mathbf{8 1 ~ k g}$ & $<\mathbf{9 0 ~} \mathbf{~ g}$ \\
\hline Age (years) & $22( \pm 3)$ & $22( \pm 2)$ & $24( \pm 3)$ & $25( \pm 2)$ \\
Body mass (kg) & $67.2( \pm 1.5)$ & $75.3( \pm 2.2)$ & $82.7( \pm 2.5)$ & $93.1( \pm 2.7)$ \\
Body height (cm) & $171( \pm 2.3)$ & $174( \pm 2.6)$ & $181( \pm 3.1)$ & $183( \pm 4.4)$ \\
BMI (Body Mass Index) & $22.5( \pm 1.6)$ & $23.6( \pm 2.1)$ & $24( \pm 1.7)$ & $27( \pm 3.1)$ \\
SMM (kg) & $34( \pm 1.4)$ & $39( \pm 2.5)$ & $45( \pm 2.1)$ & $46.5( \pm 2.5)$ \\
ExSLL [W] & $1734.5( \pm 16.2)$ & $1712.0( \pm 28.7)$ & $1679.2( \pm 46.8)$ & $1711.7( \pm 13.4)$ \\
ExSUL [W] & $617.5( \pm 21.2)$ & $615.7( \pm 10.1)$ & $665.2( \pm 14.3)$ & $752.5( \pm 15.5)$ \\
SELL [\%] & $87.9( \pm 2.3)$ & $89.7( \pm 2.9)$ & $92.2( \pm 3.2)$ & $91.3( \pm 6.4)$ \\
SEUL [\%] & $76.3( \pm 6.8)$ & $76.8( \pm 7.5)$ & $82.5( \pm 7.8)$ & $80.6( \pm 8)$ \\
\hline
\end{tabular}

SMM, Skeletal Muscle Mass.

\subsection{Procedures}

Up to $24 \mathrm{~h}$ prior to testing, all volunteers were recommended to avoid strenuous exercise as well as resistance. They were informed about the research protocol and possible risks as well the benefits of the study, and then gave informed written consent to participate in the study. The respondents were allowed to withdraw from participation in the tests at any stage of the experiment. The research 
protocol was approved by the Bioethics Committee for Scientific Research at the Jerzy Kukuczka Academy of Physical Education in Katowice. The tests were conducted in the Strength and Power Laboratory of the Academy of Physical Education in Katowice on Keiser Power Rack and Keiser Squat A300 strength training devices.

\subsection{Data Collection}

Body weight and body composition were determined using the InBody 570 electric impedance analyzer. The selected strength tests concerned the lower and upper limbs. The tests were carried out twice (every two weeks) during the pre-competitive season in the morning, after a 10-min warm-up of 5 min of work on the cycle ergometer at low intensity followed by several strength exercises without load, involving the upper and lower body. The included bench press on the Keiser Power Rack hydraulic resistance device and squats on the Keiser Squat hydraulic resistance training system. The one repetition maximum test (1RM) on the Keiser Squat and Keiser Power Rack was determined based on the protocol for the number of repetitions used by Baechle et al. [24]. After a warm-up according to the protocol used by Saeterbakken et al. [25], the participants carried out several maximum repetitions so that the number covered a range of 3 to 8 maximum repetitions. Based on the formula, the value of 1RM was calculated and used to calculate the value of the load used by each athlete to perform tests of explosive strength and strength endurance [24]. To evaluate the explosive strength, the athletes tested performed two repetitions at maximum speed while maintaining the correct technique with a load of 50\% 1RM. Strength endurance was examined during a $30 \mathrm{~s}$ test, with athletes performing 30 repetitions (1 repetition per second) with the frequency controlled by the metronome. In both tests, the participants performed exercises at maximum speed. The athletes were verbally motivated during each test. A 15-min rest interval for a full recovery was administered between the tests. The tests were performed according to the following protocol: Explosive Strength Lower Limbs (ExSLL) [W] (a test of 2 repetitions of squat below the right angle at maximum speed with a load of $50 \%$ 1RM), Strength Endurance Lower Limbs (SELL) [\%] (a test of 30 repetitions of squat below the right angle, performed continuously without rest, with a load of 50\% 1RM), Explosive Strength Upper Limbs (ExSUL) [W] (a test of 2 repetitions of the bench press at maximum speed with a load of $50 \%$ 1RM), and Strength Endurance Upper Limbs (SEUL) [\%] (a test of 30 repetitions of the bench press, performed continuously without rest, with a load of 50\% 1RM). In the case of SELL and SEUL variables, the percentage of power decrement index determined by the ratio of mean values between the 1st and 30 th repetitions was used for the analysis.

\subsection{Statistical Analysis}

The most useful methods and tools of statistical analysis were applied and tested. The significance level was set at $p<0.05$. The normality of distribution of the variables was verified using the Shapiro-Wilk test. The results of the tests clearly showed that the variables had a normal or close to normal distribution $(p>0.05)$.

All relationships between the variables studied were determined using correlation analysis and the Pearson correlation coefficient. If statistically significant correlations were found, further relationships were studied to determine the size of the effect of the independent on the dependent variable. The relationships between the dependent variable (ranking score) and the other analyzed variables (predictors) were estimated using the one-factor ridge regression analysis [26-29].

After simplification, the biometric regression model received the following (formula (1)):

$$
\mathrm{Y}=\mathrm{F}\left(\mathrm{x} \_1, \ldots, \mathrm{x} \_\mathrm{k} ; \mathrm{a} \_1, \ldots, \mathrm{a} \_\mathrm{p}\right)+\varepsilon=\mathrm{F}(\mathrm{x}, \mathrm{a})+\varepsilon
$$

where: $\quad x \_j-$ determinant variable $\left(x=\left|x \_1, \ldots, x \_k\right|^{T}\right), a \_j-$ parameter $\left(a=\left|a \_1, \ldots, a \_p\right|^{T}\right)$, $\varepsilon$-random component (also known as random factor or measurement error). 
In conclusion, a complementary analysis of statistical data was carried out using the Statistica software package (StatSoft Company, Statistica 12, Krakow, Krakow, Poland, version 2020)

\section{Results}

The results of correlation analyses between the variables of explosive strength and strength endurance of the lower and upper limbs and the ranking score (PJA) are presented in Table 2:

Table 2. Correlations of explosive strength with variables of strength endurance of the lower and upper limbs in weight categories of 66, 73, 81 and $90 \mathrm{~kg}$ and the ranking score (PJA).

\begin{tabular}{|c|c|c|c|c|}
\hline Variable & ExSLL & SELL & SEUL & ExSUL \\
\hline \multicolumn{5}{|c|}{ CATEGORY: 66 kg } \\
\hline Y-PT & 0.893 * & $0.762 *$ & 0.741 * & 0.713 * \\
\hline \multicolumn{5}{|c|}{ CATEGORY: $73 \mathrm{~kg}$} \\
\hline Y-PT & 0.424 * & 0.658 * & 0.664 * & 0.595 * \\
\hline \multicolumn{5}{|c|}{ CATEGORY: $81 \mathrm{~kg}$} \\
\hline Y-PT & $0.636^{*}$ & 0.888 * & 0.389 & 0.640 * \\
\hline \multicolumn{5}{|c|}{ CATEGORY: $90 \mathrm{~kg}$} \\
\hline Y-PT & 0.443 & 0.815 * & 0.848 * & 0.531 * \\
\hline
\end{tabular}

The results show that, in the group of judo athletes from the $66 \mathrm{~kg}$ category, fitness significant correlations between the ranking score (PJA) and all analyzed variables were observed. The ExSLL variable showed the strongest correlation. In the $73 \mathrm{~kg}$ category, significant correlations between the ranking score and the analyzed variables were also observed. However, ExSLL and ExSUL correlations with $Y$ were not strong. The SEUL and SELL variables were most strongly correlated. In the $81 \mathrm{~kg}$ category, significant correlations were found between Y and ExSUL, SELL, and. ExSLL No significant correlations with the SEUL variable were observed. The SELL variable showed the strongest correlation. In the $90 \mathrm{~kg}$ category, strong and significant correlations were observed between Y and SELL and SEUL. However, the correlation found for the ExSLL variable was significant but not very strong. No significant correlations were observed for the ExSLL variable. The SEUL variable in this weight category was most strongly correlated (Table 2).

The biometric models designed for individual weight categories is shown in Table 3:

Table 3. Biometric models of significant ranking predictors among the variables of explosive strength and strength endurance of the lower and upper limbs in particular weight categories (66, 73, 81 and $90 \mathrm{~kg})$.

\begin{tabular}{|c|c|c|c|}
\hline Variable & Beta & B & $p$ \\
\hline \multicolumn{4}{|c|}{ CATEGORY 66 kg-Y1_J66; $\mathrm{R}^{2}=0.838$} \\
\hline constant & & 201.967 & 0.021 \\
\hline ExSLL & 0.775 & 61.611 & 0.022 \\
\hline SELL & 0.424 & 19.694 & 0.031 \\
\hline \multicolumn{4}{|c|}{ CATEGORY $73 \mathrm{~kg}-\mathrm{Y} 2 \_J 73 ; \mathrm{R}^{2}=0.871$} \\
\hline constant & & 201.432 & 0.026 \\
\hline ExSLL & 0.719 & 19.412 & 0.025 \\
\hline SELL & 0.670 & 9.911 & 0.026 \\
\hline \multicolumn{4}{|c|}{ CATEGORY $81 \mathrm{~kg}-\mathrm{Y} 3 \_J 81 ; \mathrm{R}^{2}=0.866$} \\
\hline constant & & 210.784 & 0.038 \\
\hline SELL & 0.683 & 41.193 & 0.022 \\
\hline \multicolumn{4}{|c|}{ CATEGORY 90 kg-Y4_J90; $R^{2}=0.956$} \\
\hline constant & & 291.052 & 0.026 \\
\hline ExSLL & 0.894 & 46.528 & 0.025 \\
\hline SELL & 0.785 & 44.03 & 0.026 \\
\hline
\end{tabular}


Multiple ridge regression analysis, advancing for the dependent variable Y1_J66_pt, allowed for the determination of the following form of regression function (Table 3) based on specific values of individual independent variables that were significant in the model (formula (2)):

$$
\text { Y1_J66_pt }=201,967+61,611 \times \text { ExSLL }+19,694 \times \text { SELL }
$$

This means that if the value of the ExSLL increases by a unit, the mean score (Y1_J66_pt) will increase by 61 points. If the value of the SELL increases by a unit, the average score (Y2_J66_pt) will increase by ca. 19 points (Table 3).

For the dependent variable Y2_J73_pt, the following form of regression function was obtained (formula (3)):

$$
\text { Y2_J73_pt }=201.432+19.412 \times \text { SEUL }+9.911 \times \text { SELL }
$$

This means that if the value of the SEUL increases by a unit, the mean score (Y2_J73_pt) will increase by 19 points. Furthermore, if the value of the SELL variable increases by a unit, the average score (Y2_J73_pt) will increase by ca. 10 points (Table 3).

For Y3_J81_pt, the following form of regression function was determined based on specific values of individual independent variables significant in the model (formula (4)):

$$
\text { Y3_J81_pt }=210.784+41.193 \times \text { SELL }
$$

This means that if the value of the SELL increases by a unit, the mean score (Y3_J81_pt) will increase by 41 points $\mathrm{T}$ (Table 3 ).

The same analysis, advancing for Y4_J90_pt, determined the following form of regression function (formula (5)):

$$
\text { Y4_J90_pt }=291.052+46.528 \times \text { SEUL }+44.030 \times \text { SELL }
$$

This means that if the value of the SEUL increases by a unit, the mean score (Y4_J90_pt) will increase by 46 points. Furthermore, if the value of the SELL increases by a unit, the average score (Y4_J90_pt) will increase by ca. 44 points (Table 3).

A regression analysis was also carried out, modeled to determine the predictors for the entire group of athletes, taking into account the weight differences in relation to the ranking point values presented in Table 4.

Table 4. Summary of ridge regression for all participants (Y5-Total; $\left.\mathrm{R}^{2}=0.922\right)$.

\begin{tabular}{cccc}
\hline Variable & Beta & B & $p$ \\
\hline constant & & 708.329 & 0.011 \\
ExSLL & 0.464 & 12.636 & 0.039 \\
SEUL & 0.387 & 10.164 & 0.041 \\
\hline
\end{tabular}

For the dependent variable Y5-Total, the following form of regression function was determined based on specific values of individual independent variables that were significant in the model (formula (6)):

$$
\text { Y5_Total }=708.329+12.636 \times \text { ExSLL }+10.164 \times \text { SEUL }
$$

This means that if the value of the ExSLL variable increases by a unit, the mean score (Y5-Total) will increase by 12 points. Furthermore, if the value of the SEUL variable increases by a unit, the average score (Y5-Total) will increase by ca. 10 points (Table 4).

\section{Discussion}

The aim of this study was to find the relationship between the tested variables of explosive strength and strength endurance of the upper and lower limbs, as well the sports performance of judo 
athletes in four weight categories. As a result, the best predictors of the sports level in judo were determined. An innovative aspect of the research was the performance of all measurements using modern measuring pneumatic devices from Keiser (Keiser Squat and Keiser Power Rack), which ensure the performance of movements with simultaneous recording of power. These devices allowed for performing the movement at maximum speed, allowing for the measurement of several variables related to muscular strength and power.

The factors responsible for success in judo can be specific to each weight category and can represent a compromise between body weight and maximizing motor skills [30].

Regression analysis showed that in the $66 \mathrm{~kg}$ category, the most significant predictor determined by the model was ExSLL, with its increase by a unit expected to lead to an increase in the score by 61 points on average. The second significant variable was SELL. This confirms the fact that the athletes in the lightweight category are fighting at a very high pace, using techniques from all groups of throwing and grappling, and are characterized by a high level of agility. Success is determined by a skillful approach to the opponent or performing a sequence of offensive actions, which is why the lower limbs are more critical in lightweight categories [31]. In the $73 \mathrm{~kg}$ weight category, the regression model determined two predictors (SEUL and SELL). The first one, with an increase by a unit, should increase the score in the (PJA) ranking by 19 points on average. Furthermore, the results of the analysis of variance proved that there was a statistically significant variation in strength endurance of the upper limbs. Higher values of the variables were achieved by athletes with fewer points in the ranking. Therefore, it can be assumed that these variables, and consequently the upper limbs, have a statistically lower impact on sports performance in judo than the lower limbs. This is confirmed by the publications by Franchini et al. [7,32] and Adam et al. [10], who, based on the results of their research, came to similar conclusions. At the same time, the model verified the results of correlation analyses in these two weight categories, confirming the obtained correlations of these two variables with scores according to (PJA). In the $81 \mathrm{~kg}$ group of athletes, the analysis of the examined variables shows that the SELL test showed higher values of this variable to the higher-ranked competitors. This might suggest that the athletes with higher sports performance had better strength endurance because they were able to maintain the measured power for longer in the periods of time of the test. Interestingly, the values determining ExSUL in this weight category were higher in lower-ranked athletes. Therefore, it can be concluded that the results of the analysis obtained in the examined group of leading Polish judokas are similar to the results of research conducted by Franchini and his colleagues $[7,32,33]$. The lower limbs are more important for achieving high scores in judo than the upper limbs and this is particularly evident in the medium and lower weight categories. In this weight category, the regression analysis showed that the most significant predictive factor determined by the regression model was SELL. An increase in the SELL by a unit should result in an improvement of 41 points. Fighting in medium weight categories is characterized by high dynamics of performed actions and frequency of their repetition. In these categories, techniques from all groups of throws are used, with attacks starting mainly with the work of the lower limbs. The athletes move much more during the fight than in heavy categories and use their lower limbs for defensive purposes, so it is critical for them to develop explosive strength and strength endurance. In the $90 \mathrm{~kg}$ group of competitors, the analysis of variance determined a statistically significant difference in SEUL. Much better results were achieved by the athletes with higher scores in the ranking. There were no statistically significant changes in the lower limb samples in this weight category. Due to the specific body build, athletes in heavy categories are characterized by a lower frequency of attacks [34]. The fight is more static, and the judo athletes focus on fighting for the grip. Therefore, the results of the analyses support the findings of other researchers that, in the heavyweight categories, SEUL and ExSUL have significantly influenced sports performance $[7,32,33,35-38]$. The regression analysis revealed that the most significant predictor was SEUL, with an increase by unit resulting in an improvement by 46 points. In these two groups, regression modeling positively verified the results of correlation analyses. In the heavier categories ( $90 \mathrm{~kg}$ and above), athletes are less likely to use techniques that require rapid body rotation and a low 
approach between the opponent's legs. More often, foot techniques and hand throwing techniques are used when a dominant grip is developed. During the grappling on the ground in heavy categories, holding techniques are more often performed, with the strength of the upper limbs playing a critical role [34]. The Y-total variable was also analyzed together for all weight categories. The ExSLL variable turned out to be the most important predictor here, with its increase by a unit resulting in a 12-point increase in the ranking. This confirms the findings that the lower limbs are more important in judo $[7,32,33]$. It should be noted that only the variables studied were used to determine the predictors, and, based on them, the improvement of results in the (PJA) ranking list can be predicted depending on the improvement of mean test values of the predictors. However, it is known that the improvement in sports performance is also affected by other variables such as aerobic capacity [39] and anaerobic capacity [40,41], training experience, technique, tactics [42,43], the level of mental and physical fitness on a specific day, judge, injuries, diet, and psyche [43-47], which were not used for this analysis. In light of the need to improve the sports skill level, the subject of modeling should be extended to include more tests and more independent variables that were not examined in the present study. These include the variables resulting from biomechanical and physiological analysis [48-50] and tactical and technical analyses [33,51,52]. Optimal improvements in the sports performance can be achieved by using comprehensive solutions that allow for a comprehensive evaluation of the potential of athletes, taking into account social, pedagogical, medical, biological, and mental indicators. Such assumptions for the choice of variables for research will be the basis for further measurements and analyses conducted by the author to develop the widest possible base of variables describing judo as a sport. The results of the research and analyses contained in this study can be used for practical applications. They can be used as tools to support the training process and contribute to its optimization. They can also serve as a tool to monitor the explosive strength and strength endurance of the lower and upper limbs. They can also be used in the recruitment and selection for judo.

The main muscles of the correct posture are the lower limbs. In judo, posture is the most important consideration. Hence, we suggest paying particular attention to the strength of the muscles of the lower extremities in the training process, which is related to the health aspect of judo practitioners.

\section{Conclusions}

There were significant intergroup and intragroup differences in the results of explosive strength and strength endurance of the lower and upper limbs. The best predictors were identified using regression modeling: ExSLL, SELL, and SEUL. Increasing the value of these predictors by a unit should significantly affect the scores in the ranking table. Correlation analysis showed that all variables that are strongly correlated with the (PJA) ranking table scores may have an effect on the sports performance.

Author Contributions: Conceptualization, M.K. and R.L.; methodology, M.K.; software, M.K., A.I., M.N.; validation, M.K., R.L. and W.B.; formal analysis, M.K., M.W.; investigation, M.K., M.W.; resources, M.K., R.L., and W.B.; data curation, M.K. and R.L.; original draft preparation, M.K., M.N.; editing, M.K., M.W., A.I., M.N.; project administration, M.K., M.N. All authors have read and agreed to the published version of the manuscript.

Funding: Analytical studies were conducted within the framework of the Ministry of Science and Higher Education grant No. NRSA4 04054.

Conflicts of Interest: The authors declare no conflict of interest. The funders had no role in the design of the study; in the collection, analyses, or interpretation of data; in the writing of the manuscript, or in the decision to publish the results.

Limitation: The limitation of the study was only males and all categories included small number of participants.

\section{References}

1. Thayse, G.; Mabliny, T.; Sara, P. Sport Science and Therapy. Available online: https://www.researchgate.net/ publication/344242813_Sports_performance_and_systems_theories (accessed on 22 October 2020).

2. Lane, A. Introduction to the special issue on combat sport. J. Sports Sci. Med. 2006, 42, 142-144. 
3. Franchini, E.; Takito, M.Y.; Nakamura, F.Y.; Matsushigue, K.A.; Peduti Dal Molin Kiss, M.A. Effects of recovery type after a judo combat on blood lactate removal and on performance in an intermittent anaerobic task. J. Sports Med. Phys. Fit. 2003, 43, 424-431.

4. Kubo, J.; Cchishaki, T.; Nakamura, N.; Muramatsu, T.; Yamamoto, Y.; Ito, M.; Saitou HKukidome, T. Differences in fat-free mass and muscle thickness at various sites according to performance level among judo athletes. J. Strength Cond. Res. 2006, 20, 654-657. [PubMed]

5. Lidor, R.; Melnik, Y.; Bilkevitz, A.; Falk, B. The ten-station judo ability test: A test of physical and skill components. Strength Cond. J. 2006, 28, 18-20. [CrossRef]

6. Kano, J. Judo (Jujutsu), 1st ed.; Edizioni Mediterranee: Roma, Italy, 1995; pp. 10-12.

7. Franchini, E.; Del Vecchio, F.B.; Matsushigue, K.A.; Artioli, G.G. Physiological Profiles of Elite Judo Athletes. Sports Med. 2011, 41, 147-166. [CrossRef] [PubMed]

8. Detanico, D.; Dal Pupo, J.; Franchini, E.; Giovana dos Santos, S. Relationship of aerobic and neuromuscular indexes with specific actions in judo. Sci. Sports 2012, 27, 16-22. [CrossRef]

9. Franchini, E.; Sterkowicz, S.; Meira, C.M.; Gomes, F.R.F.; Tani, G. Technical Variation in a Sample of High Level Judo Players. Percept. Mot. Ski. 2008, 106, 859-869. [CrossRef]

10. Adam, M.; Tabakov, S.; Klimowicz, P.; Paczoska, B.; Laskowski, R.; Smaruj, M. The efficiency of judo techniques in the light of amendments to the rules of a sports contest. J. Combat Sports Martial Arts 2012, 3, 115-120. [CrossRef]

11. Brandt, R.; Bevilacqua, G.G.; Crocetta, T.B.; Monteiro, C.B.; Guarnieri, R.; Hobold, E.; Flores, L.J.F.; Miarka, B.; Andrade, A. Comparisons of mood states associated with outcomes achieved by female and male athletes in high-level judo and brazilian jiu-jitsu championships: Psychological factors associated with the probability of success. J. Strength Cond. Res. 2019, 1-7. [CrossRef]

12. Zatsiorsky, V.; Kraemer, W. Science and Practice of Strength Training; Human Kinetics: Champaign, IL, USA, 2006; pp. 155-167.

13. Szeligowski, P. Trening Siły Eksplozywnej W Sportach Walki; Wyd. AHA: Łódź, Poland, 2012; Volume 1.

14. Sterkowicz, S.; Franchini, E. Techniques used by judoists during the world and olympic tournaments 1995-1999. Hum. Mov. 2000, 2, 23-33.

15. Kraemer, W.; Fleck, S.; Evans, W. Strength and power training: Physiological mechanisms of adaptation. Exerc. Sport Sci. Rev. 1996, 24, 363-397. [CrossRef] [PubMed]

16. Alemany, J.; Pandorf, C.; Montain, S.; Castellani, J.; Tuckow, A.; Nindl, B. Reliability Assessment of Ballistic Jump Squats and Bench Throws. J. Strength Cond. Res. 2005, 19, 33-38. [PubMed]

17. Wilson, G.; Newton, R.; Murphy, A.; Humpheries, B. The optimal load for the development of dynamic athletic performance. Med. Sci. Sport Exerc. 1993, 25, 1279-1286. [CrossRef]

18. Brown, L.; Weir, J. ASEP procedures recommendation I: Accurate assessment of muscular strength and power. J. Exerc. Physiol. Online 2001, 4, 1-21.

19. Bompa, T.; Haff, G. Periodization: Theory and Methodology of Training; Human Kinetics: Champaign, IL, USA, 2009.

20. Smaruj, M.; Orkwiszewska, A.; Adam, M.; Jeżyk, D.; Kostrzewa, M.; Laskowski, R. Changes in Antrophometric Traits and Body Composition over a Four-Year Period in Elite Female Judoka Athletes. J. Hum. Kinet. 2019, 70, 131-140. [CrossRef] [PubMed]

21. Gepfert, M.; Filip, A.; Kostrzewa, M.; Królikowska, P.; Hajduk, G.; Trybulski, R.; Krzysztofik, M. Analysis of power output and bar velocity during various techniques of the bench press among women. J. Hum. Sport Exerc. 2020, 16, 1-9. [CrossRef]

22. Judo, P.Z. Available online: http://web.pzjudo.pl/ (accessed on 27 September 2020).

23. Baechle, T.R.; Earle, R.W.; Wathen, D. Essentials of Strength Training and Conditioning; Human Kinetics: Champaign, IL, USA, 2008; pp. 381-412.

24. Sæterbakken, A.; van den Tillaar, R.; Fimland, M. A comparison of muscle activity and 1-RM strength of three chest-press exercises with different stability requirements. J. Sport Sci. 2011, 29, 1-6. [CrossRef]

25. Ostasiewicz, S.; Rusnak, Z.; Siedlecka, U. Statystyka. Elementy Teorii I Zastosowania; Wydawnictwo Akademii Ekonomicznej we Wrocławiu: Wrocław, Poland, 2006.

26. Keele, L.; Kelly, J.N. Dynamic Models for Dynamic Theories: The Ins and Outs of Lagged Dependent Variables. Political Anal. 2006, 14, 186-205. [CrossRef] 
27. Maszczyk, A.; Gołaś, A.; Pietraszewski, P.; Roczniok, R.; Zając, A.; Stanula, A. Application of neural and regression models in sports results prediction. Procedia Soc. Behav. Sci. 2014, 117, 482-487. [CrossRef]

28. Maszczyk, A.; Gołaś, A.; Czuba, M.; Król, H.; Wilk, M.; Goodwin, J.; Stastny, P.; Kostrzewa, M.; Zając, A. EMG analysis and modelling of the flat bench press using artificial neural networks. S. Afr. J. Res. Sport Phys. Educ. Recreat. 2016, 38, 95-103.

29. Prasitio, D.; Harlili, D. Predicting football match results with logistic regression. In Proceedings of the 2016 International Conference on Advanced Informatics: Concepts, Theory and Application (ICAICTA), Penang, Malaysia, 16-19 August 2016.

30. Callister, R.; Callister, R.J.; Staron, R.S.; Fleck, S.J.; Tesch, P.; Dudley, G.A. Physiological characteristics of elite judo athletes. Int. J. Sports Med. 1991, 12, 196-203. [CrossRef]

31. James, L.P.; Beckam, E.M.; Kelly, V.G.; Haff, G.G. The neuromuscular qualities of higher and lower level mixed martial arts competitors. Int. J. Sports Physiol. Perform. 2017, 12, 612-620. [CrossRef]

32. Franchini, E.; Brito, C.J.; Fukuda, D.H.; Artioli, G.G. The physiology of judo-Specific training modalities. J. Strength Cond. Res. 2014, 28, 1474-1481. [CrossRef]

33. Franchini, E.; Takito, M.; Kiss, M.; Sterkowicz, S. Physical fitness and anthropometrical differences between elite and non-elite judo players. Biol. Sport 2005, 22, 315-328.

34. Pujszo, R.; Adam, M.; Kuźmińska, A.; Błach, W. The course of the judo fight in the heaviest category $(+100 \mathrm{~kg})$ seen from the perspective of attacks in the standing position, based on the Olympic Games in London 2012. Ido Mov. Cult. J. Martial Arts Anthropol. 2014, 14, 63-71.

35. Buśko, K.; Nowak, A. Changes of maximal muscle torque and maximal power output of lower extremities in male judoists during training. Hum. Mov. 2008, 9, 111-115. [CrossRef]

36. Fagerlund, R.; Häkkinen, H. Strength profile of Finnish judoists-Measurement and evaluation. Biol Sport 1991, 8, 143-149.

37. Lewandowska, J.; Buśko, K.; Pastuszak, A.; Boguszewska, K. Somatotype variables related to muscle torque and power in judoists. J. Hum. Kinet. 2011, 30, 21-28. [CrossRef]

38. Sánchez, Á.G.; Domínguez, A.S.; Turpin, J.A.P.; Tormo, J.M.C.; Llorca, C.S. Importance of hand-grip strength as an indicator for predicting the results of competitions of young judokas. Arch. Budo 2011, 7, 167-172.

39. Laskowski, R.; Wysocki, K.; Multan, A.; Haga, S. Changes in cardiac structure and function among elite judoists resulting from long-term judo practice. J. Sports Med. Phys. Fit. 2008, 48, 366-370.

40. Ikai, M.; Haga, S.; Kaneko, M. The characteristics of physical fitness of judoists from the viewpoint of respiratory and cardiovascular functions. Bull. Assoc. Sci. Stud. Judo Kodokan Rep. 1972, 4, 105-110.

41. Zdanowicz, R.; Wojcieszak, I.; Wojczuk, J. Cykloergometryczny Test Wydolności Anaerobowej; Wojcieszak, I., Ed.; Wydolnościowe testy specjalne. Wdrożenia; Wydaw. Inst. Sportu: Warszawa, Poland, 1985; pp. 9-25.

42. Rixon, K.P.; Lamont, H.S.; Bemden, M.G. Influence of type of muscle contraction, gender, and lifting experience on postactivation potentiation performance. J. Strength Cond. Res. 2007, 21, 500-505.

43. Roczniok, R.; Stanula, A.; Maszczyk, A.; Mostowik, A.; Kowalczyk, M.; Fidos-Czuba, O.; Zając, A. Physiological and physical profiles and on-ice performance approach to predict talent in male youth ice hockey players during draft to hockey team. Isokinet. Exerc. Sci. 2013, 21, 121-127. [CrossRef]

44. Behm, D.G.; Button, D.C.; Butt, J.C. Factors affecting forceloss with prolonged stretching. Can. J. Appl. Physiol. 2001, 26, 261-271. [CrossRef]

45. Morales, J.; Garcia, V.; García-Massó, X.; Salvá, P.; Escobar, P.; Buscà, B. The Use of Heart Rate Variability in Assessing Precompetitive Stress in High-Standard Judo Athletes. Int. J. Sports Med. 2013, 34, 144-151. [CrossRef] [PubMed]

46. Morales, J.; Alamo, J.M.; Garcia-Masso, X.; Busca, B.; Lopez, J.L.; Serra-Ano, P.; Gonzalez, L.M. Use of Heart Rate Variability in Monitoring Stres and Recovery in Judo Athletes. J. Strength Cond. Res. 2014, 28, 1896-1905. [CrossRef]

47. Vacher, P.; Nicolas, M.; Mourot, L. Monitoring training response with heart rate variability in elite adolescent athletes: Is there a difference between judoka and swimmers? Arch. Budo 2016, 12, 35-42.

48. Judge, L. Key elements of hammer biomechanics. In the 16th International Track E Field Coaches Association Congress Proceedings; U.S. Track \& Field and Cross Country Coaches Association: New Orleans, LA, USA, 2004; pp. 182-184.

49. Knudson, D. Fundamentals of Biomechanics; Springer Science and Business Media, LLC: Berlin, Germany, 2007. 
50. Sterkowicz, S.; Gabryś, T.; Szmatlan-Gabryś, U.; Stanula, A.; Garnys, M. The interdependence of the main indicators of five methods applied to determine the lactate anaerobic threshold in judo athletes. Arch. Budo 2016, 12, 35-41.

51. Sterkowicz, S.; Lech, G.; Almansba, R. The course of fight and the level of sports achievements in judo. Arch. Budo 2010, 6, 1-6.

52. Miarka, B.; Cury, R.; Julianetti, R.; Battazza, R.; Julio, U.F.; Calmet, M.; Franchini, E. A comparison of time-motion and technical-tactical variables betweenage groups of female judo matches. J. Sport Sci. 2014, 2, 1-10.

Publisher's Note: MDPI stays neutral with regard to jurisdictional claims in published maps and institutional affiliations.

(C) 2020 by the authors. Licensee MDPI, Basel, Switzerland. This article is an open access article distributed under the terms and conditions of the Creative Commons Attribution (CC BY) license (http://creativecommons.org/licenses/by/4.0/). 